\title{
Gestão participativa no Sistema Municipal de Meio Ambiente: um estudo em Condado-PB
}

Cada vez mais é necessário à participação da sociedade civil na tomada de decisões junto ao poder público, principalmente no que diz respeito ás questõe ambientais. Nesta perspectiva este estudo teve como objetivo identificar a participação na estruturação do Sistema Municipal de Meio Ambiente do Município de Condado-PB. Para tanto, adotou-se a abordagem qualitativa, quanto a sua natureza a pesquisa denomina-se como descritiva e para instrumento de estudo utilizou-se a pesquisa documental. O estudo foi realizado no Munícipio de Condado na Mesorregião do Sertão Paraibano, onde foram analisados os instrumentos de participação presentes no Município. Identificaram-se instrumentos e órgãos de grande relevância instituídos formalmente, no entanto percebeu-se o desconhecimento de tais políticas por parte da população e a não valorização e atuação desses instrumentos no que se refere à gestão local.

Palavras-chave: Gestão Ambiental; Legislação; Participação; SISMUMA.

\section{Participatory management in the Municipal Environment System: a study in Condado-PB}

It is increasingly necessary for society to participate in decision-making with the government, especially with regard to environmental issues. In this perspective this study aimed to identify the participation in the structuring of the Municipal Environment System of the Municipality of Condado-PB. For this, the qualitative approach was adopted, as its nature the research is called as descriptive and for the study instrument documentary research was used. The study was carried out in the County Municipality in the Mesoregion of Sertão Paraibano, where the instruments of participation present in the Municipality were analyzed. Instruments and bodies of great relevance formally instituted were identified, however, it was noticed the lack of knowledge of such policies by the population and the lack of appreciation and performance of these instruments with regard to local management.

Keywords: Environmental Management; Legislation; Participation; SISMUMA

Topic: Planejamento, Gestão e Políticas Públicas Ambientais

Reviewed anonymously in the process of blind peer.

Antônio Augusto Martins dos Santos

Universidade Estadual da Paraíba, Brasil

http://lattes.cnpq.br/0501855605107487

antoniomsipb@gmail.com

Talita Linhares Soares

Universidade Estadual da Paraíba, Brasi

http://lattes.cnpq.br/9709312783067468

talita10lins@gmail.com

Lucas Andrade de Morais

Universidade do Estado do Rio Grande do Norte, Brasil

http://lattes.cnpq.br/4304836710800316

http://orcid.org/0000-0003-4443-2393

ucasmorais7@gmail.com
Received: 10/04/2021

Approved: 15/05/2021
Eunice Ferreira Carvalho (iD)

Universidade Estadual da Paraíba, Brasi

http://lattes.cnpq.br/0787250920518181

http://orcid.org/0000-0002-2333-1342

elocarvalho12@gmail.com

Cícero Otávio de Lima Paiva (iD

Universidade do Estado do Rio Grande do Norte, Brasil

http://lattes.cnpq.br/7862529637329670

http://orcid.org/0000-0003-3740-4191

cicero.otavio@hotmail.com

\section{Referencing this:}

SANTOS, A. A. M.; SOARES, T. L.; MORAIS, L. A.; CARVALHO, E. F.; PAIVA, C. O. L.. Gestão participativa no Sistema Municipal de Meio Ambiente: um estudo em Condado-PB. Natural Resources, v.11, n.2, p.127-132, 2021. DOI: http://doi.org/10.6008/CBPC2237$\underline{9290.2021 .002 .0013}$ 


\section{INTRODUÇÃO}

A Gestão Ambiental tem ganhado destaque no governo a nível municipal, especialmente após a instituição da Política Nacional de Meio Ambiente (PNMA) no ano de 1981 e a promulgação da Constituição Federal de 1988 (CARVALHO et al., 2005). Esses dois marcos normativos inseriram o meio ambiente como pauta de proteção e promoção, criando instrumentos que habilitaram a participação de diversos atores nas gestões ambientais nos três níveis de esferas do Poder Público. Em nível de estruturação da gestão ambiental local o Sistema Municipal de Meio Ambiente (SISMUMA) se constitui como o conjunto de órgãos municipais que tem por função a preservação do meio ambiente, e o uso consciente dos recursos naturais, garantindo o desenvolvimento local e a sustentabilidade da localidade.

Alguns mecanismos contribuem para a ação do SISMUMA como as políticas públicas do município, e a participação social, assim como a atividade de entidades deliberativas como o Conselho Municipal de Meio Ambiente (ÁVILA et al., 2012). Tendo em vista que a questão ambiental é uma discussão recorrente no âmbito acadêmico, político e social, cabe à gestão pública municipal estabelecer instrumentos legais, e espaços para a atuação da população, em assuntos que dizem respeito à realidade ambiental local. Nunes Jr. et al. (2012), apontam que "para que haja uma efetiva gestão ambiental no âmbito municipal é necessária à participação da sociedade nos processos de gestão". Portanto este trabalho tem como objetivo identificar a gestão participativa na estruturação do sistema municipal de meio ambiente do município de Condado, localizado no sertão paraibano.

\section{REVISÃO TEÓRICA}

A Constituição Federal de 1988 inaugura um novo cenário na política brasileira, findo o período ditatorial, inicia-se o período de redemocratização, momento em que não somente o voto é a única forma de atuação da população, mas também a participação em conselhos e nas diversas esferas da gestão pública surgem para democratizar as instituições e decisões referentes a setores da administração pública no país. Na Constituição Federal de 1988 encontram-se claros sinais da luta pela democratização da gestão pública, quando nela se garantiu, por exemplo, o princípio da gestão descentralizada e participativa. Nos artigos 204 e 227, a Carta Constitucional assegura a participação da população, por meio de organizações representativas, no processo de formulação e controle das políticas públicas em todos os níveis da gestão administrativa: municipal, estadual e federal (ROCHA, 2009).

A maior participação popular é um fator positivo, uma vez que legitima a população participar ativamente de temas que Ihes dizem respeito especialmente em relação à gestão ambiental municipal. A Constituição Federal institui em seu artigo 225 que todos tem direito ao meio ambiente equilibrado, e cabe ao poder público e sociedade defendê-lo. Para tanto existem meios que irão auxiliar esses atores no desenvolvimento e na melhoria do meio ambiente na localidade.

Com a promulgação da Lei no 6.938 foi instituída a Política Nacional de Meio ambiente (PNMA), no ano de 1981, o meio ambiente passou a ser pauta de promoção e discussão em diversas esferas do poder público desde o âmbito federal até o âmbito municipal. A partir desta lei, especificamente em seu artigo 6으 
são elencados os órgãos e entidades da União, dos Estados, do Distrito Federal, dos Territórios e dos Municípios que serão responsáveis pelo tratamento das questões ambientais e que constituirão o Sistema Nacional de Meio Ambiente - SISNAMA (BRASIL, 1981).

Ainda no artigo 6으 da citada lei estão delimitados alguns órgãos que fazem parte do SISNAMA e suas finalidades, são eles o Conselho Nacional de Meio Ambiente (CONAMA), o IBAMA, e o Instituto Chico Mendes. Por fim está estabelecida a atuação dos estados e municípios que também irão participar dos processos, programas e políticas referentes ao meio ambiente em seus respectivos campos de atuação e dentro de suas competências. (BRASIL, 1981), tais órgãos possuem caráter articulador, informativo, fiscalizador, consultivo, formador dentre outros (NOVICKI et al., 2010)

Com a possibilidade de desenvolvimento de ações na esfera estadual, e principalmente na esfera municipal, o poder de discussão e decisão estão mais próximos da população que pode participar de tal processo de desenvolvimento, a partir de organismos e entidades de participação da sociedade. A criação de organismos de participação popular nas políticas públicas foi um meio encontrado para melhorar a qualidade dos serviços e das políticas públicas e permitir que representações sociais tivessem acesso ao governo, dando início ao processo de maior interação entre o governo e as representações sociais, compartilhando a responsabilidade por tomadas de decisões sobre alguns problemas públicos. (PINTO et al., 2018).

Dentre os organismos e entidades que podem facilitar a participação popular, no tratamento das questões ambientais a nível municipal, cabe salientar a atuação do Sistema Municipal de Meio Ambiente (SISMUMA).

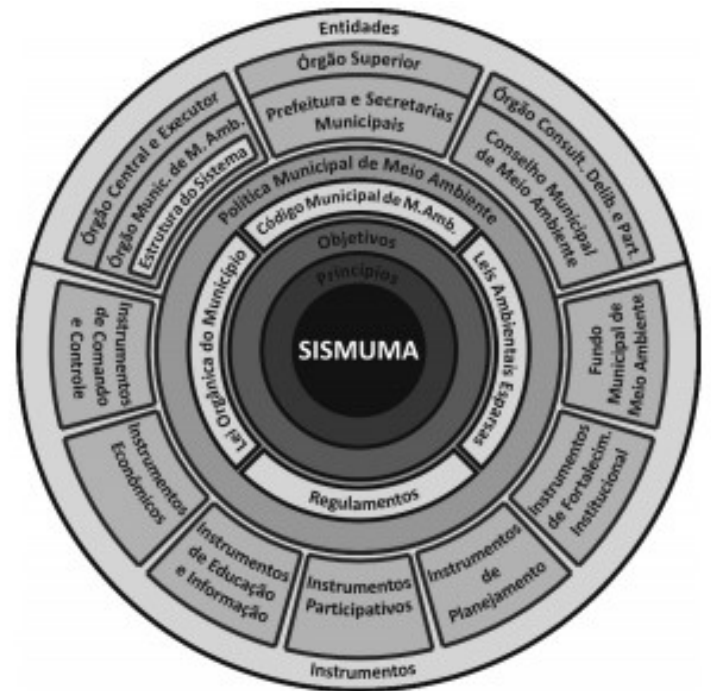

Figura 1: Estruturação do SISMUMA. Fonte: Ávila \& Malheiros (2012).

Como aponta a Figura 1 o SISMUMA é constituído por um conjunto de órgãos, políticas e instrumentos estes de diferentes naturezas. De forma conjunta e integrada governo e sociedade devem trabalhar para que estes órgãos desempenhem suas devidas atribuições, para garantir a proteção do meio ambiente, assim como o desenvolvimento sustentável do município.

Em que pese exista uma gama de órgãos que compõe o SISMUMA destaca-se que os mesmos trabalham de forma integrada e multidisciplinar, tendo em vista a complexidade que permeia a temática 
ambiental (GUIMARÃES, 2015).

\section{METODOLOGIA}

A pesquisa é caracterizada pela abordagem qualitativa, pois busca a descrição assim como a compreensão e explicação de um problema ou fenômeno da realidade. Definindo-se quanto aos fins como uma pesquisa descritiva, pois este expõe características de uma determinada população ou fenômeno e estabelecer correlação entre variáveis; Quanto aos instrumentos de pesquisa, trata-se de uma pesquisa documental, pois é realizada com documentos conservados de órgãos públicos qualquer natureza, através de regulamentos, regimentos internos, ofícios, diários, dentre outros, que por se tratar de informações de acesso público, não se tem a necessidade de ser registrada a investigação pelo sistema CEP/CONEP Resolução no 510/2016, CNS (VERGARA, 2016).

A pesquisa foi realizada no município de Condado-PB, no qual verificou-se a estruturação do SISMUMA no que tange aos instrumentos e entidades, como a existência de legislação ambiental, políticas, programas, conselhos e fundo de meio ambiente, com intuito de correlacionar a teoria com a prática, ou seja, de entender/descrever como a legislação presente tem proporcionado a gestão participativa no município.

A cidade de Condado está localizada na região oeste do Estado da Paraíba, na Mesorregião do Sertão Paraibano. O município possui uma área territorial de 265,473 km², conta com uma população 6.584 pessoas, sua densidade demográfica é de 17,31(hab./Km), tendo como vegetação predominante à caatinga-sertão (IBGE, 2019). Seu clima é quente e úmido e possui temperaturas de 340 C e mínima de 28QC e ainda encontra-se inserido na bacia Hidrográfica do Rio Piranhas, região do Médio Piranhas (CONDADO, 2020).

\section{RESULTADOS E DISCUSSÕES}

O Sistema Municipal de Meio Ambiente, é a estruturação da gestão ambiental nos municípios, possuindo objetivos, princípios, legislações/regulamentos, política de meio ambiente, instrumentos e entidades que proporciona a proteção e promoção ambiental local.

São vários os instrumentos de participação que compõem o SISMUMA, como órgãos consultivos e deliberativos, nesta categoria se destaca a atuação do Conselho Municipal de Meio Ambiente. Além deste o Fundo Municipal de Meio Ambiente também é considerado um instrumento do SISMUMA, (ÁVILA; MALHEIROS, 2012). Estes quando desempenhados com eficiência garantem assim a participação efetiva da sociedade civil, bem como uma gestão ambiental eficiente. Dessa forma, este estudo buscou-se analisar o Sistema Municipal de Meio Ambiente na cidade de Condado-PB, verificando que os instrumentos existentes e a sua funcionalidade são: Conselho Municipal de Meio Ambiente (CMMA) - foi criado pela lei municipal n 389 de 10 de maio de 2013, de acordo com o seu artigo segundo é um órgão consultivo de assessoramento ao Poder Executivo Municipal e deliberativo no âmbito de sua competência, sobre as questões ambientais propostas nesta e demais leis correlatadas do município (CONDADO, 2013); Órgão 
Municipal de Meio Ambiente - No município de Condado-PB a secretaria municipal de meio ambiente, está incorporada com a secretaria municipal de Agricultura, a partir da Lei municipal $n^{\circ} 285$ de 13 de novembro de 2006; Fundo Municipal de Meio Ambiente - foi instituído pela Lei Municipal n 388 de 10 de maio de 2013, e tem como finalidade mobilizar e gerir recursos para o financiamento de planos, projetos e programas que visem o uso racional de recursos ambientais, melhoria na qualidade do meio ambiente, promoção da educação ambiental, e proteção do meio ambiente (CONDADO, 2013); Instrumento Participativo - Nessa categoria o município dispõe da Agenda 21 local instituído pela lei municipal n²27-A de 28 de novembro de 2001. A Agenda 21 local é um processo de planejamento que envolve governo e participação social com o intuito de construir um Plano local de desenvolvimento sustentável, a partir da elaboração de projetos, onde governo e sociedade civil estarão envolvidos nas diversas fases de tais projetos (MMA).

Nestes termos, dos órgãos que compõem o SISMUMA na cidade de Condado-PB identificaram-se quatro instrumentos de grande importância para uma melhor gestão ambiental, que atuam de forma geral com a interação do poder público com a sociedade civil garantindo assim propostas e ações para o desenvolvimento sustentável do município. Todavia verificou-se a não atuação desses órgãos e instrumentos no município, existindo formalmente, porém não desempenhando sua função na prática. 0 conselho de meio ambiente encontra-se inativo, o fundo municipal de Meio ambiente foi apenas instituído legalmente, assim como a agenda 21 local, desses o único órgão que atua é a secretaria de agricultura e meio ambiente, o que pode ser explicado pela sua fusão.

\section{CONCLUSÕES}

O município de Condado-PB dispõe de vários instrumentos legais que tratam da questão ambiental na gestão local, para tanto, os mesmos como mencionados anteriormente em suas maiorias não são efetivos. Outro fator que dificulta a gestão ambiental local é a falta de conhecimento da existência de tais políticas ambientais por grande parte da população, vale salientar que apesar destes instrumentos serem instituídos legalmente e as respectivas leis estarem disponíveis para o acesso público nos portais do município, ocorre a não divulgação das ações desempenhadas, bem como da importância desses órgãos de forma mais ampla. Assim Rodrigues et al. (2012) afirma que "a sistematização das informações pertinentes às ações empreendidas pela administração pública local poderia ser motivadora de uma postura de participação da sociedade na gestão ambiental local.".

Dessa forma percebe-se a atuação da gestão ambiental voltada a dimensão legal, com instrumentos instituídos formalmente, todavia esses órgãos não exercem ou nunca exerceram seu devido funcionamento. Não havendo atualmente na prática o desenvolvimento de ações desenvolvidas através desses instrumentos. Percebe-se ainda a não valorização dessas políticas e de sua eficácia para o desenvolvimento sustentável do município e para participação efetiva da sociedade civil na tomada de decisões em meio a questões ambientais.

Como ponto de partida para mudar da gestão ambienta municipal seria necessário à gestão local 
promover algum tipo de evento, ou utilizar as mídias sociais para dá à população conhecimento maior de tais políticas, e posteriormente fazer com que esses instrumentos desempenhassem seu funcionamento, isso resultaria em um avanço para passos maiores rumo à sustentabilidade do município.

Portanto cabe a gestão pública da cidade de Condado-PB, fazer com que os instrumentos legais expostos anteriormente como o Conselho Municipal de Meio Ambiente e Fundo Municipal de Meio Ambiente, o programa da Agenda 21 local, estejam atuando na gestão ambiental da localidade, de maneira integrada com a população, que conhece os problemas e adversidades pelo qual o município passa, sendo assim a participação social é de suma importância para o tratamento da gestão ambiental a nível municipal.

\section{REFERÊNCIAS}

ÁVILA, R.; MALHEIROS, T.. O Sistema Municipal de Meio Ambiente no Brasil: avanços e desafios. Saúde e Sociedade, v.21, p.33-47, 2012.

BRASIL. Lei no 6.938. Dispõe sobre a Política Nacional do Meio Ambiente, seus fins e mecanismos de formulação e aplicação, e dá outras providências. Brasília: DOU, 1981.

PREFEITURA MUNICIPAL DE CONDADO-PB. Lei municipal $\mathbf{N}^{\circ}$ 285. Cria e regulamenta a Secretaria de Meio Ambiente Municipal em fusão com a Secretária Municipal de Agricultura de Condado, Estado da Paraíba, e dá outras providências. Condado, 2006.

PREFEITURA MUNICIPAL DE CONDADO-PB. Lei municipal $\mathbf{N}^{\circ}$ 389. Dispõe sobre a criação do Conselho Municipal de Meio Ambiente COMMAC e dá outras providências. Condado, 2013.

PREFEITURA MUNICIPAL DE CONDADO-PB.. Lei municipal $\mathbf{N}^{\circ}$ 388. Cria o Fundo municipal de meio ambiente nos termos da Lei Federal $N^{\circ}$ 6.938, de 31 de agosto de 1981 e dá outras providências. Condado, 2013.

PREFEITURA MUNICIPAL DE CONDADO-PB. Lei municipal $\mathbf{N}^{\circ}$ 227. Cria o Programa da Agenda 21 local e dá outras providências. Condado, 2001.

CARVALHO, P.; OLVEIRA, S.; BARCELLOS, F.; ASSIS, J.. Gestão Local e Meio Ambiente. Ambiente \& Sociedade, v.8, 2005

PREFEITURA MUNICIPAL DE CONDADO-PB. História.

Condado, 2020.

GUIMARÃES, M.. A Dimensão Ambiental na Educação. 12 ed. Campinas: Papirus, 2015.
IBGE. Cidades: censo de 2019. IBGE, 2020.

MMA. Ministério Do Meio Ambiente. Agenda 21 local: 2004. 2020.

NOVICKI, V.; SOUZA, D. B.. Políticas públicas de educação ambiental e a atuação dos conselhos de meio ambiente no Brasil: perspectivas e desafios. Ensaio (Fundação Cesgranrio. Impresso), v.18, p.711-736.

NUNES, M. R.; PHILIPPI JR, A.; FERNANDES, V.. A Atuação de Conselhos do Meio Ambiente na Gestão Ambiental Local. Saúde e Sociedade, v.21, n.3, p.48-60, 2012.

PINTO, T.; MARTINS, S.; LEONEL, D.; CKAGNAZAROFF, I.. Governança Participativa: possibilidades e desafios na gestão local. Interações, v.19, n.3, p.627-641, 2018.

ROCHA, R. A.. gestão descentralizada e participativa das políticas públicas no Brasil. Revista Pós Ciências Sociais, v.6, n.11, 2009

RODRIGUES, M.; MALHEIROS, T.; FERNANDES, V.; DARÓS, D.. A Percepção Ambiental Como Instrumento de Apoio na Gestão e na Formulação de Políticas Públicas Ambientais. Saúde e Sociedade, v.21, n.3, p.96-110, 2012.

SILVA, C. V. T.; DIAS, N. S.; OLIVEIRA JÚNIOR, H. S.; SILVA, C. L. C.; LIMA, A. O.; TEIXEIRA, R. O.; MIRANDA, P. E. M.. Análise da estrutura do sistema municipal de meio ambiente no município de Macau, Rio Grande do Norte, Brasil. Revista Espacios, v.39, n.8, 2018

VERGARA, S. C.. Projetos e relatórios de pesquisa em administração. São Paulo: Atlas, 2016

A CBPC - Companhia Brasileira de Produção Científica (CNPJ: 11.221.422/0001-03) detém os direitos materiais desta publicação. Os direitos referem-se à publicação do trabalho em qualquer parte do mundo, incluindo os direitos às renovações, expansões e disseminações da contribuição, bem como outros direitos subsidiários. Todos os trabalhos publicados eletronicamente poderão posteriormente ser publicados em coletâneas impressas sob coordenação da Sustenere Publishing, da Companhia Brasileira de Produção Científica e seus parceiros autorizados. Os (as) autores (as) preservam os direitos autorais, mas não têm permissão para a publicação da contribuição em outro meio, impresso ou digital, em português ou em tradução. 